Adhesion of Cells, Viruses and Nanoparticles 

Kevin Kendall • Michaela Kendall

Florian Rehfeldt

\section{Adhesion of Cells, Viruses and Nanoparticles}

粤 Springer 
Professor Kevin Kendall

Chemical Engineering

University of Birmingham

Edgbaston B15 2TT

UK

K.Kendall@bham.ac.uk

Dr Michaela Kendall

Peninsula College of Medicine

and Dentistry

The Knowledge Spa

Truro

Cornwall TR1 3HD

UK

m.kendall@ex.ac.uk
Dr Florian Rehfeldt

Georg-August-Universität Göttingen

3rd Institute of Physics - Biophysics

Friedrich-Hund-Platz 1

37077 Göttingen

Germany

rehfeldt@physik3.gwdg.de

ISBN 978-90-481-2584-5

e-ISBN 978-90-481-2585-2

DOI 10.1007/978-90-481-2585-2

Springer Dordrecht Heidelberg London New York

Library of Congress Control Number: 2010937429

(c) Springer Science+Business Media B.V. 2011

No part of this work may be reproduced, stored in a retrieval system, or transmitted in any form or by any means, electronic, mechanical, photocopying, microfilming, recording or otherwise, without written permission from the Publisher, with the exception of any material supplied specifically for the purpose of being entered and executed on a computer system, for exclusive use by the purchaser of the work.

Printed on acid-free paper

Springer is part of Springer Science+Business Media (www.springer.com) 


\section{Preface}

It is now 100 years since adhesion of cells was shown to be vital for their growth and reproduction. Ross Granville Harrison, Fig. 1, invented the technique for culturing cells, a technique which is now of massive importance for studying genetics, cancer, tissue engineering and disease processes.

Harrison was a 37 year old lecturer at Johns Hopkins in the USA, observing the growth of nerve fibres in embryos, when he found that he could insert solid blood clot material into the animal and the cells would continue to propagate along the

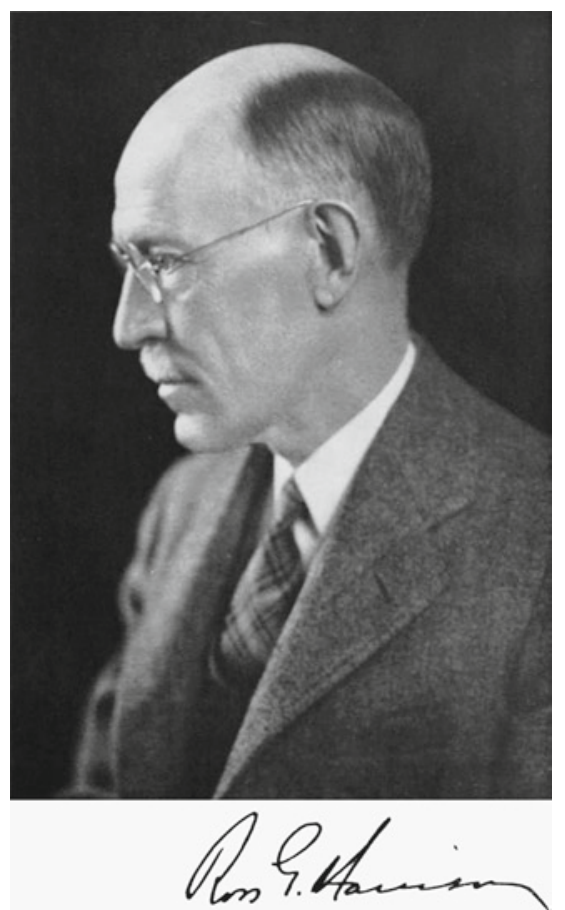

Fig. 1 Ross Granville Harrison 1870-1959 (with permission of Royal Society) 
foreign material. Subsequently in 1907 he found that the nerve cells would also grow on the blood clot in a dish outside the embryo. In his 1914 paper, ${ }^{2}$ he then showed that the shape of the cells depended on the solid substrate by testing the cells on clotted plasma, spider web fibres and glass cover slips. This was the first indication that adhesion was essential for shape and differentiation of cells.

It is interesting that 100 years have also elapsed since the discovery that viruses can cause animal disease. Ellerman and Bang ${ }^{3}$ in 1908 showed that leukaemia could be transmitted to chickens by injecting cell free material. A few years later, Rous $^{4}$ in 1910 and 1911 showed that solid tumours could be transferred from chicken to chicken to spread the disease and also isolated the infective agent in a cell free filtrate. It later became clear that the virus particles, which at that time could not be imaged by microscopy, were adhering to the cells to cause infection. Rous received the Nobel Prize for this work in 1966, more than 50 years after his observations. There was no model at that time to describe the mechanism by which the virus particle attached to and entered the cell.

The idea that fine particles in smoke caused damage to humans goes back much further: it is said that the city of London imposed smoke control in the thirteenth century because coal fires were 'prejudicial to health'. ${ }^{5}$ However, the understanding of the mechanisms of toxicity has only recently emerged. The particles in smoke, which are approximately the same size as cells or viruses, somehow adhere to the lung surfaces and cause organ failure, even heart disease. How does this adhesion process occur? Similarly, it was observed ${ }^{5}$ in the nineteenth century that chimney sweeps suffered disease from the soot which contacted them; 'I have known 8 or 9 sweeps lose their lives by the soot cancer. The parts which it seizes are entirely eaten off'. We examine some of the processes which contribute to nanoparticle toxicity in Chapter 11.

Ever since Robert Hooke ${ }^{6}$ viewed a slice of cork using his early microscope (Fig. 2), showing for the first time 'Cells distinct from one another', but clearly adhering very strongly to form the strong lightweight porous wood material, we have been fascinated by the adhesion forces which hold large multicellular organisms together. The purpose of this book is to address the description, definition and understanding of these adhesion forces in relation to three systems.

- Inanimate fine particles

- Virus particles

- Cells

In recent times, the theoretical idea which has dominated the field is that of the adhesion molecule, a complex protein like fibronectin for example, as described by Hynes. ${ }^{7}$ Such molecules have been thought to control the adhesion of cells. Indeed, an enormous amount of work has been done by thousands of scientists to define various adhesion molecules, whose range, variety, complexity and nomenclature have expanded substantially over the past decades ${ }^{8-19}$ Unfortunately, the 'lock and key' model on which this science has been based, also around a century old, ${ }^{20}$ is unacceptable. While there is no doubt that a coating of fibronectin on a surface definitely helps cell adhesion, we aim to show in this book that the adhesion 


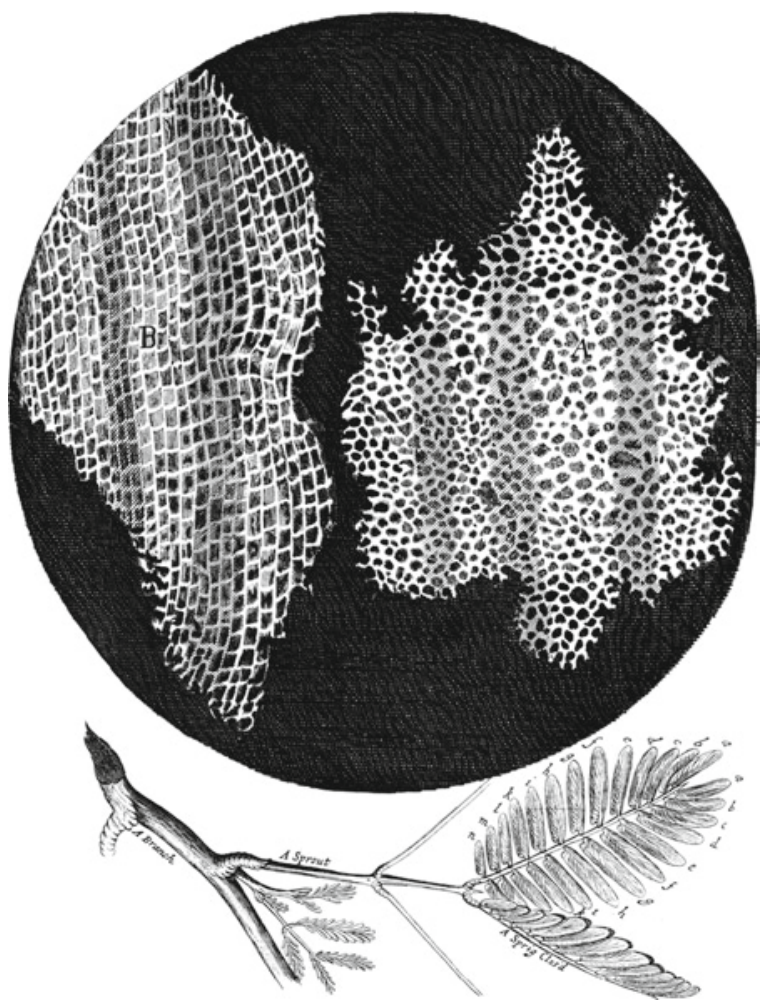

Fig. 2 Illustration from Robert Hooke's book which first showed cells and the adherence between them $^{6}$ (with permission of Royal Society)

molecule is only one factor in the equation. Van der Waals forces are the key cause of the adhesion. Substrate elasticity and geometry are also important. In addition we aim to show that there are complex mechanisms such as Brownian motion and surfactant molecules in solution which display major effects.

Originally, the theoretical ideas used in this book were defined ${ }^{21,22}$ in 1970-1971. By considering the contact of elastic bodies, it became evident that three parameters generally entered the equation for adhesive force $F$, as indicated below.

$$
F=K\left[W E d^{3} /\left(1-v^{2}\right)\right]^{1 / 2}
$$

where $K$ was a constant, $W$ the work of adhesion in $\mathrm{Jm}^{-2}, E$ the elastic modulus in $\mathrm{Pa}, v$ the Poisson's ratio and $\mathrm{d}$ the dimension in metres. From this model, it is clear that the adhesion molecules have an effect on $W$, but elasticity $E, v$ is equally influential and the geometry $d$ is much more important. The most surprising thing about this new theory was that adhesion force was strongest when the surfaces were absolutely smooth and clean, with no adhesion molecules present. In other words the effect of adhesion molecules was to reduce the adhesion force, not to cause the adhesion force as intimated in references. ${ }^{7-19}$ The purpose of this book is to show 
that this new theory gives a much more satisfactory account of the results than the simplistic adhesion molecule lock and key models which have dominated during the last century. Part 1 deals with the fundamentals, the phenomenology and the theory, Part II goes on to describe the mechanisms and measurements at both macroscopic and nanoscopic levels, then Part III looks at detailed research in adhesion of nanoparticles, viruses and cells.

In this endeavour, we have been assisted by many colleagues.

In particular KK and MK express thanks to Patricia Kendall for constant support over 40 years.

KK thanks the late David Tabor who set him on the path to studying this field and to Ken Johnson, Alan Roberts and Alan Gent who have been partners since 1966.

MK wishes to thank Morton Lippmann, Bob Maynard, Teresa Tetley and Howard Clark for timely advice, to Uludag University for solid support, and KK for making it all fun.

FR wishes to thank his mentors Erich Sackmann, Motomu Tanaka and Dennis E Discher for continuous support and inspiration and Andre EX Brown and Peter Zwiauer for critical reading and fruitful discussions.

If you have any comments on the ideas expressed here, please email us on k.kendall@bham.ac.uk,m.kendall@ex.ac.uk and rehfeldt@physik3.gwdg.de

February 2010

Kevin Kendall, Michaela Kendall and Florian Rehfeldt

\section{References}

1. Abercrombie, M, Biographical Memoirs of fellows of the Royal Society, 7 (1961) 110-126.

2. Harrison, R.G., The reaction of embryonic cells to solid structures, J Expt Zool 17 (1914) 521-44.

3. Ellerman, C. and O. Bang. Centralbl. Bakteriol. 46 (1908) 595-609.

4. Rous, P. J. Exp. Med. 12 (1910) 696-705; Rous, P. J. Exp. Med. 13 (1911) 397-411

5. www.ace.mmu.ac.uk; British Parliamentary Papers, Session No.13, 1863: Report from the Committee of the House of Commons.

6. Hooke, R., Micrographia, Royal Society London 1665, available on www.gutenberg.net.

7. Hynes, R.O., Fibronectins, Springer Verlag, New York 1990.

8. Springer, T.A., Adhesion receptors of the immune system, Nature 346 (1990) 425-34.

9. Hortsch, M., Nott, P., New Cell Adhesion research, Nova Science 2009.

10. Umemori, H., The sticky synapse: Cell adhesion molecules, Springer Berlin 2009.

11. Garrod, D. R., Structure and function in cell adhesion, Portland Press 2008.

12. Cress, A.E., Nagle, R.B., (eds.), Cell adhesion and cytoskeletal molecules in metastasis, Springer, Dordrecht 2006.

13. Beckerle, M.C., (ed.), Cell Adhesion, Oxford University Press 2002.

14. Ley, K., (ed.), Adhesion molecules: function and inhibition, Birkhauser, Basel 2007.

15. Reutter, W., Schuppan, D., Tauber, R., Zeitz, M., Falk symposium, Cell adhesion molecules in health and disease, Kluwer 2003.

16. Coutts, A.S., Adhesion protein protocols, Humana Press London $2^{\text {nd }}$ Ed 2007.

17. Behrens, J., Nelson, W.J., Cell adhesion, Springer Berlin 2004. 
18. Collins, T., Leukocyte recruitment, endothelial cell adhesion molecules..., Kluwer Dordrecht 2001.

19. Barker, J., McGrath, J., (eds.), Cell adhesion and migration..., Harwood Academic Amsterdam 2001.

20. Kaufmann, S.H.E., Elie Metchnikoff and Paul Ehrlich's impact on infection biology, Microbes and Infection 10 (2008) 1417-9.

21. Kendall, K., The adhesion and surface energy of elastic solids, J PhysD: Appl Phys 4 (1971) $1186-95$

22. Kendall, K., Molecular adhesion and its applications; the sticky universe, Kluwer, New York 2001, chapter 12 . 



\section{Contents}

\section{Part I Fundamentals}

1 Background to Adhesion of Cells, Viruses and Nanoparticles ........... 3

1.1 The Problem of Understanding Adhesion .................................... 4

1.2 van der Waals Forces Cause Adhesion .......................................... 5

1.3 Adhesion Molecules: Learning from the Gecko............................... 6

$1.4 \quad$ False Hypotheses .......................................................................... 7

1.5 van der Waals Force.................................................................... 8

1.6 Difference Between van der Waals and Electrostatic Forces: Yeast Adhesion ......................................................................... 9

$1.7 \quad$ Fall in Adhesion Under Water .......................................................... 11

1.8 The Short Range of van der Waals Force ....................................... 12

1.9 Measurement of van der Waals Force on Polymer Spheres........... 13

1.10 Effect of Contaminant Molecules on the Surfaces ....................... 15

1.11 Effect of Roughness................................................................ 16

1.12 Effect of Elasticity on Adhesion ................................................... 17

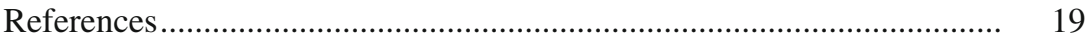

2 Phenomenology of Adhesion: From Macro- to Nano-Systems ........... 21

2.1 Showing the van der Waals Adhesion Force ................................... 22

2.2 The First Demonstration of Nanoparticle Adhesion........................ 23

2.3 Arguments Against van der Waals Adhesion ................................ 25

2.4 Definition of van der Waals Adhesion ............................................. 25

2.5 Definition of $W$, the Work of Adhesion in Peeling ........................ 27

2.6 Nature of Bonds in the Equilibrium Theory of Adhesion ............ 28

2.7 Bradley's Adhesion Rule ........................................................... 29

2.8 The Significance of Bradley's Rule ................................................ 32

2.9 Adhesion of Spheres; Hertz Theory ............................................. 34

2.10 The JKR Contribution.................................................................. 35

2.11 The Nature of Adhesive Contact Between Polymer Spheres ....... 37

2.12 Application to Nanoparticles, Viruses and Cells ........................... 38

2.13 Conclusions.......................................................................... 42

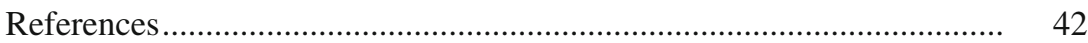


3 Modelling Nanoparticle, Virus and Cell Adhesion

3.1 Two Parameter Model of Atomic Interaction Force and Energy

3.2 Demands on the Model ................................................................ 48

3.3 Modelling Simple Nanoparticle Adhesion .................................. 50

3.4 Sodium Chloride Nanoparticle Results .................................... 52

3.5 Elastic and Plastic Adhesion....................................................... 54

3.6 Influence of Surface Contamination ......................................... 55

3.7 Effect of Surfactants ............................................................ 58

3.8 Proteins as Surfactants ............................................................. 61

3.9 Models of Polymer 'Adhesion Molecule' ...................................... 64

3.10 Membrane Models .......................................................................... 65

3.11 Three Components: Surface, Water, Adhesion Molecule............. 66

3.12 Conclusions............................................................................ 68

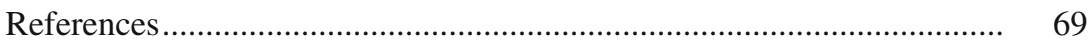

\section{Part II Mechanisms}

4 Macroscopic View of Adhesion for Nanoparticles,

Viruses and Cells ........................................................................... 75

$4.1 \quad$ Fundamental Definitions........................................................... 75

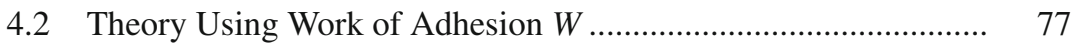

4.3 Different Geometries; Wedging, Peeling and Spheres ................ 78

4.4 Effect of Elasticity; Scraping and Stretching.............................. 79

4.5 More Complex Geometries; Button Test, Tension and Probes ............................................................. 81

4.6 Measured Values of Adhesion Energy ............................................. 83

4.7 Reducing $W$ by Adding Surface Active Agents........................... 84

4.8 Measurements of Cell Adhesion by Probe Methods ................... 87

4.9 Crack Stopping by Geometry Change ........................................ 89

4.10 Elastic Changes Affecting Adhesion: Shrinkage and Pre-stressing ................................................................ 92

4.11 Stringing and Crazing ............................................................. 94

4.12 Biofilm Adhesion................................................................... 96

4.13 Conclusions......................................................................... 97

References......................................................................... 98

5 Statistics of Adhesion at Nanoscale ................................................. 101

5.1 The Flickering Black Spot; Large Contacts............................. 101

5.2 The Flickering Black Spot; Small Contacts................................ 103

5.3 The Dwell-Time Effect ............................................................ 104

5.4 Reaching Equilibrium ............................................................. 106

5.5 Adhesion with Water Present at Surfaces .................................. 108

5.6 Adhesive Drag ................................................................ 110

5.7 Adhesive Hysteresis............................................................... 111 
5.8 Peel Stopping by Viscoelastic Loss

5.9 Rolling Resistance as a Measure of Adhesion Hysteresis, Drag and Dwell-Time Effect

5.10 Aggregation Statistics of Nano-Particles .................................. 117

5.11 Conclusions....................................................................... 120

References......................................................................... 120

6 Subdivision and Separation of Contact Spots .................................. 123

6.1 Increase in Adhesion Force for Subdivided Contact Spots .......... 123

6.2 Force Versus Energy ................................................................. 125

6.3 Peeling Off the Gecko Foot ..................................................... 127

6.4 Measurement of Single Seta Adhesion Force............................. 128

6.5 Possibility of Adhesive Dislocations ........................................ 129

6.6 Subdividing Contact Spots Increases Adhesion ......................... 132

6.7 Gecko Tape ....................................................................... 133

6.8 Micro-Patterning ................................................................. 136

6.9 Stiffness and Adhesion of Multiple Contacts ........................... 138

6.10 Conclusions.......................................................................... 141

References.................................................................... 142

7 Measurement Methods .................................................................. 145

7.1 Light Microscopy................................................................... 146

7.2 Reflectance Interference Contrast Microscopy.......................... 147

7.3 Fluorescence Microscopy, Interference Contrast, Total Internal Reflection ....................................................... 148

7.4 Atomic Force Microscopy ......................................................... 149

7.5 Optical Tweezers....................................................................... 151

7.6 Micropipette Aspiration............................................................ 152

7.7 Spinning Disc.................................................................... 152

7.8 Cell Adhesion by Flow Methods ................................................ 153

7.9 Cell Counting Methods.............................................................. 157

7.10 Adhesion by Counting Doublets ............................................ 158

7.11 Experimental Results ........................................................... 161

7.12 Conclusions.......................................................................... 163

References........................................................................... 164

\section{Part III Detailed Research}

8 Adhesion of Nanoparticles ......................................................... 169

8.1 Nanoparticles in Space ........................................................ 169

8.2 Nanoparticles in the Atmosphere........................................... 171

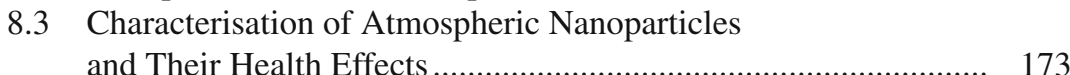

8.4 Nanoparticles in Water........................................................ 176

8.5 Synthetic Nanoparticle Polymers; Latex Coalescence ................ 178 
8.6 Synthetic Inorganic Nanoparticles ............................................... 180

8.7 Gas-Phase Nanoparticle Production .......................................... 183

8.8 Liquid Phase Preparation of Nanoparticles ............................... 184

8.9 New Method for Nanoparticle Tracking ..................................... 186

8.10 Adhesion from Doublet Numbers.............................................. 188

8.11 Detection of Adhesion with FemtoNewton Resolution................ 190

8.12 Conclusions.............................................................................. 191

References............................................................................. 191

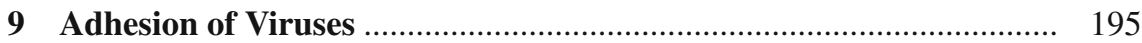

$9.1 \quad$ Variety of Virus Particles ........................................................ 196

9.2 Observing the Adhesion of Viruses by TEM \& X-Ray ............... 197

9.3 TEM Investigations of Adhesion Mechanism ............................ 199

9.4 Atomic Force Microscope (AFM) Studies .................................. 200

9.5 Sensor Methods for Detecting Adhesion .................................... 204

9.6 Single Particle Fluorescence..................................................... 206

9.7 Self Adhesion and Aggregation by Light Scattering .................. 208

9.8 Virus Calibration Using Standard Polystyrene Latex .................. 211

9.9 Self-Adhesion of Viruses .......................................................... 212

9.10 Drug Treatments Associated with Adhesion .............................. 213

9.11 Preventing Virus Detachment ................................................. 216

9.12 Conclusions.......................................................................... 218

References......................................................................... 218

10 Adhesion of Cells ............................................................................ 221

10.1 Cell Adhesion Is a Vital Phenomenon ..................................... 221

10.2 The Emergence of Cell Culture as Investigative Tool .................. 223

10.3 Factors in Cell Adhesion - More than Lock and Key ................................................................. 224

10.4 Substrate Elasticity and Cell Health ........................................ 227

10.5 Model Systems for Cell Adhesion Measurements...................... 228

10.6 Substrate Geometry Effects on Cell Health ................................. 231

10.7 Elasticity Drives Stem Cell Differentiation ............................... 233

10.8 Physical Models for Cell-Substrate Interactions ........................ 233

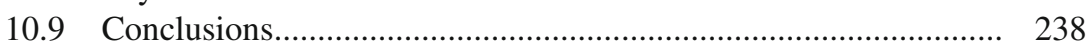

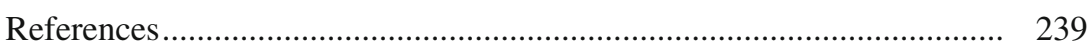

11 Nanoparticles Adhering to Cells; Toxicity Effects ......................... 241

11.1 Pathways into the Body ...................................................... 241

11.2 Variety of Nanoparticles ..................................................... 243

11.3 Measures of Nanoparticle Toxicity ......................................... 245

11.4 Nanoparticle Surface Interactions with
Extracellular Molecules ....................................................... 246

11.5 Nanoparticles Approaching the Cell Surface............................ 249

11.6 Nanoparticles Entering Cells .................................................... 251 
11.7 Toxicity Mechanics ..................................................................... 253

11.8 Translocation of Nanoparticles Within Organisms ................... 256

11.9 Nanoparticle Toxicity: Lessons from the Lung........................ 257

11.10 Conclusions ........................................................................ 260

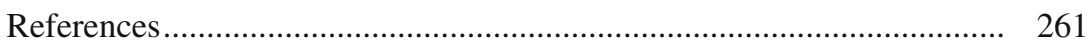

12 Cell, Virus and Nanoparticle Adhesion: Significance and Future..... 265

12.1 Key Questions of Adhesion ................................................ 265

12.2 Adhesion Fundamentals..................................................... 267

12.3 Adhesion at the Molecular Level ........................................... 268

12.4 Subdivision of Contact Spots ............................................ 270

12.5 Connexion Between Nanoparticles, Viruses and Cells .............. 272

12.6 Future Problems and Trends ............................................... 273

12.7 A Vision of the Future ......................................................... 274

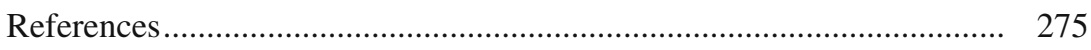

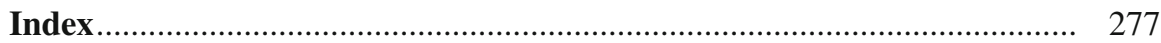


